\title{
The Role of OmpC and OmpF in Acidic Resistance in Escherichia coli
}

\author{
Amany Bekhit, Toshihiko Fukamachi, Hiromi Saito, and Hiroshi Kobayashi* \\ Graduate School of Pharmaceutical Sciences, Chiba University; Chiba 260-8675, Japan. \\ Received October 14, 2010; accepted December 22, 2010
}

The roles of $\mathrm{OmpC}$ and $\mathrm{OmpF}$ in acidic resistance (AR) were examined. When ompC and ompF were deleted, AR was decreased. The decreased level of AR seen in the mutant that was deficient in ompC and ompF was elevated by the addition of glutamate, but not by the addition of arginine or lysine. The expression levels of $a d i A$ and $c a d B$ were diminished by the deletion of $o m p C$ and $o m p F$, and the conversion of arginine to agmatine and lysine to cadaverine by intact cells were reduced in the mutant. The expression of $\operatorname{gad} A / \operatorname{gadB}$ was not affected by the deletion of $о m p C$ and $о m p F$. These results suggest that the transport of arginine, lysine, and their decarboxylated products through OmpC and/or OmpF is essential for the survival of Escherichia coli cells under extremely acidic conditions.

Key words acidic resistance; OmpC; OmpF; Escherichia coli

Bacteria are able to survive under many harsh conditions. For example, pathogenic bacteria are often exposed to extremely acidic $\mathrm{pH}$ in the stomach and phagosomes, which threaten their survival. Survival under such conditions depends on the presence of adaptive systems that sense the acidic environment and coordinate appropriate molecular responses. ${ }^{1)}$ It is therefore important to clarify these response mechanisms in order to increase our understanding of bacterial physiology and pathogenesis.

It is proposed that Escherichia coli (E. coli) mainly achieve this through three acidic resistance (AR) systems, AR1, AR2, AR3 ${ }^{2,3)}$ All of these systems provide different levels of protection. ${ }^{4}$ While AR2 and AR3 employ specific decarboxylase/antiporter systems requiring external glutamate (AR2) or arginine (AR3), the mechanism behind AR1 has not yet been clearly defined. Moreover, it has been proposed that a lysine-dependent system involving lysine decarboxylase might constitute an additional AR system (AR4). ${ }^{5}$ Arginine and lysine decarboxylases are strongly induced at low $\mathrm{pH}$ in the presence of their amino acid substrates under anaerobic conditions. ${ }^{6}$ )

$E$. coli possesses a number of outer membrane proteins (OMP), some of which play an important role in the specific or nonspecific membrane transport of hydrophilic molecules, such as ions, amino acids, and sugars. ${ }^{78}$ Among these OMP, OmpC (which has a molecular mass of $36 \mathrm{kDa}$ ) and $\mathrm{OmpF}$ (which has a molecular mass of $35 \mathrm{kDa}$ ) are often regarded as classical porins and are present in large quantities. ${ }^{9,10)} \mathrm{Al}-$ though it has been proposed that OmpC and $\mathrm{OmpF}$ are required under some harsh conditions in Gram-negative bacteria, ${ }^{11)}$ E. coli cells are able to grow in the absence of these porin proteins. ${ }^{12)}$ It therefore remains to be clarified under which conditions porin proteins are required for $E$. coli growth. An E. coli mutant that was deficient in $o m p R$, a gene that regulates the expression of ompC and ompF, demonstrated poor survival under strong acidic conditions. ${ }^{13)}$ However, the roles of OmpC and OmpF are still unknown because $\operatorname{ompR}$ has been proposed to regulate many genes other than ompC and omp $F^{14,15)}$

Our present study was carried out to elucidate the roles of $\mathrm{OmpC}$ and $\mathrm{OmpF}$ in E. coli acidic resistance by investigating the expression of amino acid decarboxylases and their activity in ompC and ompF deficient mutants. We found that
OmpC and OmpF play essential roles in the acidic resistance of $E$. coli in the presence of arginine and lysine. This result suggests that the transport of some substrates is required for survival under acidic conditions because the outer membrane is the first barrier between Gram-negative bacteria and the surrounding environments.

\section{MATERIALS AND METHODS}

Bacterial Strains and Growth Conditions The E. coli strains and plasmids used in this study are listed in Table 1. E. coli cells were grown at $37^{\circ} \mathrm{C}$ in minimal EG medium consisting of $\mathrm{E}$ medium ${ }^{16)}$ and $0.4 \%$ glucose. E medium contained $73 \mathrm{~mm} \mathrm{~K}_{2} \mathrm{HPO}_{4}, 17 \mathrm{~mm} \mathrm{NaNH} \mathrm{HPO}_{4}, 10 \mathrm{~mm}$ citric acid, and $0.8 \mathrm{~mm} \mathrm{MgSO}_{4} \cdot{ }^{16}$ ) The medium $\mathrm{pH}$ was adjusted with $\mathrm{HCl}$ or $\mathrm{KOH}$. When required, ampicillin $(100 \mu \mathrm{g} / \mathrm{ml})$, kanamycin $(25 \mu \mathrm{g} / \mathrm{ml})$, and chloramphenicol $(20 \mu \mathrm{g} / \mathrm{ml})$ were added.

Bacterial growth was monitored by measuring the absorbance of the culture media at $600 \mathrm{~nm}$. The cell density at an absorbance of 0.3 was approximately $2 \times 10^{8}$ colony-forming units $(\mathrm{CFU}) / \mathrm{ml}$ under our experimental conditions.

Table 1. Bacterial Strains and Plasmids Used in This Study

\begin{tabular}{|c|c|c|}
\hline Strains & Relevant genotype & Reference or source \\
\hline MKW505 & MH621 ompF $F^{+}$ & 12) \\
\hline MH621 & $\begin{array}{l}\text { MH20 } \Phi(\text { ompF-lacZ) hyb. } 16-21 \\
\text { ompF } F^{-} \text {omp } C^{+}\end{array}$ & 21) \\
\hline KAEC5 & MH621 ompF $F^{+}$ompC:: $\mathrm{Km}^{\mathrm{r}}$ & 12) \\
\hline W3110 & $\begin{array}{l}\lambda^{-} \mathrm{F}^{-} \text {derived from wild type } \\
\text { E. coli } \mathrm{K}-12\end{array}$ & Lab stock \\
\hline BW25113 & $\begin{array}{l}\text { lacIq } r r n B_{\mathrm{T} 14} \Delta l a c Z_{\mathrm{WJ} 16} h s d R 514 \\
\Delta a r a B A D_{\mathrm{AH} 33} \Delta r h a B A D_{\mathrm{LD} 78}\end{array}$ & 33) \\
\hline FBW25 & BW25113 ompF:: $\mathrm{Cm}^{\mathrm{r}}$ & Lab stock $^{a)}$ \\
\hline WOF25 & $\mathrm{W} 3110$ ompF $:: \mathrm{Cm}^{\mathrm{r}}$ & $\begin{array}{l}\text { Lab stock, W3110 } \times \mathrm{P} 1 \\
\text { (FBW25) }\end{array}$ \\
\hline $\mathrm{ABC} 2010$ & MH621 ompF:: $\mathrm{Cm}^{\mathrm{r}}$ omp $C:: \mathrm{Km}^{\mathrm{r}}$ & $\begin{array}{l}\text { This study, KAEC } 5 \times \mathrm{P} 1 \\
\text { (WOF } 25 \text { ) }\end{array}$ \\
\hline $\begin{array}{l}\text { Plasmids } \\
\text { pompF } \\
\text { pompC }\end{array}$ & $\begin{array}{l}\text { pNT3-ompF } \\
\text { pNTR-SD-ompC }\end{array}$ & $\begin{array}{l}\text { mobile plasmid collection }^{b)} \\
\text { mobile plasmid collection }^{b)}\end{array}$ \\
\hline
\end{tabular}

a) Constructed by one-step gene disruption, as described previously. ${ }^{33)}$ b) $\mathrm{Ob}-$ tained from the National BioResource Project (National Institute of Genetics, Mishima, Japan): E. coli. 
Acid Resistance Assay Cells precultured in LB medium at $\mathrm{pH} 7$ were diluted 1000 -fold with EG medium at $\mathrm{pH} 5.5$ and then cultured at $37^{\circ} \mathrm{C}$ until their absorbance at $600 \mathrm{~nm}$ reached 0.3 . The cells were grown either aerobically with shaking or anaerobically in tightly capped 6-ml glass tubes filled with growth medium without shaking in a static incubator. The cells were then diluted 40-fold with EG medium at $\mathrm{pH}$ 2.4. The $\mathrm{pH}$ of the resulting medium was $2.5 \pm 0.02$. After an acidic challenge at $\mathrm{pH} 2.5$ at $37^{\circ} \mathrm{C}$, the culture medium was diluted with phosphate-buffered saline (PBS) consisting of $137 \mathrm{~mm} \mathrm{NaCl}, 2.7 \mathrm{~mm} \mathrm{KCl}, 4.3 \mathrm{mM} \mathrm{Na}_{2} \mathrm{HPO}_{4}$, and $1.4 \mathrm{~mm}$ $\mathrm{KH}_{2} \mathrm{PO}_{4}$ at $\mathrm{pH} 7.4$, and the colony forming unit $(\mathrm{CFU}) / \mathrm{ml}$ was determined after the cells had been plated onto LB agar plates, followed by overnight incubation at $37^{\circ} \mathrm{C}$. AR was represented as the percentage ratio of $\mathrm{CFU} / \mathrm{ml}$ after the acidic challenge at $\mathrm{pH} 2.5$ to that before the challenge. Viability was measured three times in all experiments, and mean values and standard deviations were obtained.

RNA Isolation and Reverse Transcription After the $E$. coli cells had been grown in EG medium at $\mathrm{pH} 5.5$ until their absorbance reached 0.3 under aerobic or anaerobic conditions, $5 \times 10^{8}$ cells were harvested. The total RNA was subsequently extracted using TRI reagent (Sigma, U.S.A.), and contaminating DNA was digested using DNase I (TakaraBio, Japan) according to the manufacturer's protocol. The concentration and purity of RNA were determined using a GeneQuant RNA/DNA Calculator (Pharmacia Biotech, Sweden). Isolated RNA was stored at $-80^{\circ} \mathrm{C}$ until use. cDNA synthesis was performed in $20 \mu \mathrm{l}$ of the reverse transcription (RT) buffer (TOYOBO, Japan) containing $0.2 \mu \mathrm{g}$ of RNA, $60 \mathrm{ng}$ of random hexamers (Invitrogen Corp., U.S.A.), 10 units of RNase inhibitor (TOYOBO), $1 \mathrm{~mm}$ of each deoxynucleoside triphosphate, and 100 units of reverse transcriptase (ReverTra Ace; TOYOBO), according to the manufacturer's protocol.

Reverse Transcription Polymerase Chain Reaction (RTPCR) The PCR mixture $(20 \mu \mathrm{l})$ consisted of 0.5 units of Taq DNA polymerase (Bio Academia), $2 \mu \mathrm{l}$ of $2 \mathrm{~mm}$ deoxynucleoside triphosphate mixture, $2 \mu$ of $10 \times$ ThermoPol buffer (NEB, U.S.A.), $1 \mu \mathrm{l}$ of $10 \mu \mathrm{m}$ each primer, and $1 \mu \mathrm{l}$ of cDNA. The PCR was performed using a PCR thermal cycler (Takara-Bio, Japan) under the following conditions: $94{ }^{\circ} \mathrm{C}$ for $1 \mathrm{~min}, 58^{\circ} \mathrm{C}$ for $1 \mathrm{~min}$, and $72{ }^{\circ} \mathrm{C}$ for $1.5 \mathrm{~min}$. The similar results were obtained with the cycle numbers of 25 and 30 , and the band densities were almost saturated with the cycle number of 35 . Therefore, the cycle number of 30 was used in Fig. 4. The PCR products were stored at $4{ }^{\circ} \mathrm{C}$. The primer

Table 2. Primers Used in This Study

\begin{tabular}{|c|c|c|}
\hline Target & Primer $\left(5^{\prime}\right.$ to $\left.3^{\prime}\right)$ & $\begin{array}{l}\text { Product size } \\
\text { (bp) }\end{array}$ \\
\hline \multirow[t]{2}{*}{$\operatorname{gad} A$} & f: AGTTCGAAATGGACCAGAAGCTGT & 266 \\
\hline & r: GTCGATCCAGTTTTTATTGATCGAC & \\
\hline \multirow[t]{2}{*}{$\operatorname{gad} B$} & f: GGAGTTTAAAATGGATAAGAAGCAAG & 270 \\
\hline & r: TTGTCGATCCAGTTTTTGTTAATG & \\
\hline \multirow[t]{2}{*}{ adiA } & f: TAACTTCTCCCGCTTCAACC & 152 \\
\hline & r: AATCAACCGCTTCGTCAATC & \\
\hline \multirow[t]{2}{*}{$c a d B$} & f: TCTTCTGTAATGGCGGCTTC & 145 \\
\hline & r: CCTGGCCTACCAACATCATC & \\
\hline \multirow[t]{2}{*}{ 16S rRNA } & f: GATCATGGCTCAGATTGAACG & 153 \\
\hline & r: CTACCGTTTCCAGTAGTTATCC & \\
\hline
\end{tabular}

sets used are listed in Table 2. The PCR products were separated on $6 \%$ polyacrylamide gel in $90 \mathrm{~mm}$ Tris-borate buffer containing $2 \mathrm{~mm}$ ethylenediaminetetraacetic acid (EDTA), at $\mathrm{pH}$ 8.2, before being stained with ethidium bromide for visualization on a UV transilluminator.

Measurement of Decarboxylase Activity Cells grown in the logarithmic growth phase in $\mathrm{EG}$ medium at $\mathrm{pH} 5.5$ were harvested, washed with $0.9 \% \mathrm{NaCl}$, and resuspended at $5 \times 10^{10}$ cells $/ \mathrm{ml}$ in the same solution. Decarboxylase activity was measured as described previously ${ }^{17)}$ with some modifications. An aliquot of cells $\left(2 \times 10^{8}\right.$ cells $)$ was suspended in $1 \mathrm{ml}$ of the assay solution containing $9 \%$ of $\mathrm{NaCl}$ and $0.1 \%$ of glutamate, arginine, or lysine, with or without Triton $\mathrm{X}$ $100(0.3 \%)$. The suspension was then incubated in a $37^{\circ} \mathrm{C}$ water bath, and the $\mathrm{pH}$ of the suspension was measured at $10 \mathrm{~min}$ intervals for $1 \mathrm{~h}$.

Other Procedures P1 transduction was carried out using the P1kc phage as described by Lennox. ${ }^{18)}$

\section{RESULTS}

Acidic Resistance (AR) in $E$. coli Mutants Deficient in ompC and $\boldsymbol{o m p F}$ In order to investigate the roles of OmpC and OmpF in the survival of $E$. coli, we initially analyzed how OmpC and OmpF deficiency affects AR. AR was somewhat decreased by the deletion of either ompC or ompF, and the AR of the mutant that was deficient in both ompC and $o m p F$ was lower than that of the strains containing both OMP (Fig. 1).

The attenuation of the AR of the mutants was recovered by the addition of plasmids containing ompF or ompC, and the multicopy expression of ompF or ompC gene in MH621/ pompF or $\mathrm{KAEC5/pompC} \mathrm{increased} \mathrm{its} \mathrm{viability} \mathrm{more} \mathrm{than}$ that of the wild type MKW505 (Fig. 1). These results clearly indicated that $\mathrm{OmpF}$ and $\mathrm{OmpC}$ have a significant impact on $E$. coli survival in extremely acidic environments. The recovery of the AR by the addition of plasmids containing ompC or $o m p F$ in the double mutant $\mathrm{ABC} 2010$ was lower than that in the single mutant, indicating that both $\mathrm{OmpC}$ and $\mathrm{OmpF}$ are required for maximum survival, although either $\mathrm{OmpC}$ or

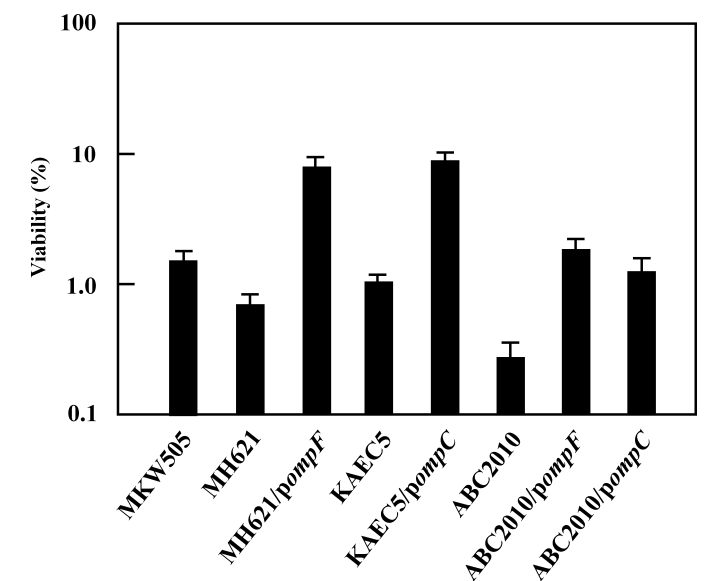

Fig. 1. The Acidic Resistance of Mutants Deficient in OMP

MKW505 (omp $C^{+}$omp $F^{+}$), MH621 (omp $C^{+}$omp $F^{-}$), MH621 containing pompF, KAEC5 (omp $\left.C^{-}, o m p F^{+}\right)$, KAEC5 containing pompC, ABC2010 (omp $C^{-}$ompF $F^{-}$), $\mathrm{ABC} 2010$ containing pompF, and $\mathrm{ABC} 2010$ containing pompC were grown aerobically in EG pH 5.5 medium and challenged in EG medium at $\mathrm{pH} 2.5$ for $1 \mathrm{~h}$, and then their viability was measured, as described in Materials and Methods. 


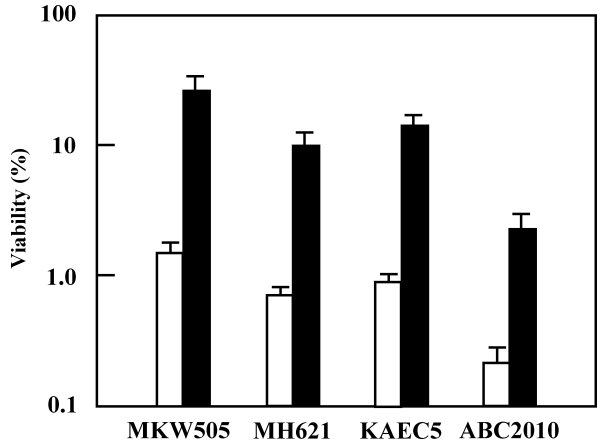

Fig. 2. Effect of Glutamate on the AR of Various Mutants

MKW505 (omp $\left.C^{+} o m p F^{+}\right)$, MH621 (omp $C^{+}$ompF $\left.F^{-}\right)$, KAEC5 (omp $C^{-}, o m p F^{+}$), and $\mathrm{ABC} 2010$ (omp $\mathrm{C}^{-} \mathrm{ompF} F^{-}$) were grown aerobically at $\mathrm{pH} 5.5$, and their viability was measured after acidic challenge at $\mathrm{pH} 2.5$ for $1 \mathrm{~h}$, as described in Materials and Methods. One millimolar glutamate was added to the culture medium at pH 5.5 (black bars). The white bars represent the AR measured without glutamate.

OmpF alone can support the survival at acidic $\mathrm{pH}$.

The Effects of OmpC and OmpF on Glutamate, Arginine, and Lysine Dependent AR Systems According to previous reported study, E. coli strains have the ability to induce acid resistance systems under different physiological conditions. $^{19)}$ AR2 requires extra-cellular glutamate and is induced at acidic $\mathrm{pH}$ under aerobic conditions, while AR3 and $\mathrm{AR} 4$ are induced by low $\mathrm{pH}$ in the presence of arginine and lysine under anaerobic conditions. ${ }^{20)}$ Therefore, we examined the effect of OmpC and OmpF on the glutamate dependent AR under aerobic conditions, while the effect on the arginine and lysine dependent AR was studied under anaerobic conditions. E. coli strains MKW505, MH621, KAEC5, and ABC2010 were treated with $1 \mathrm{~mm}$ glutamate (AR2) in EG medium with a $\mathrm{pH}$ of 5.5 under aerobic conditions and then challenged in EG medium with a $\mathrm{pH}$ of 2.5. The addition of glutamate enhanced the AR 12-fold in the MKW505 cells, 13-fold in the MH621 cells, 15-fold in the KAEC5 cells, and 8-fold in the ABC2010 cells (Fig. 2). The similar increases in the AR of the four strains suggested that the roles of $\mathrm{OmpC}$ and $\mathrm{OmpF}$ in $\mathrm{AR}$ are not mediated by the glutamate-dependent system (AR2).

In contrast, the survival rate of the double deficient mutant was not significantly increased after the addition of $1 \mathrm{~mm}$ arginine (AR3) or lysine (AR4) to EG medium under anaerobic conditions (Fig. 3). On the other hand, the presence of arginine or lysine protected the single mutants and the wild type strains against acidic stress (Fig. 3). Furthermore, the protection induced by arginine or lysine in the double deficient mutant was restored by complementation with plasmids containing ompC or ompF (Fig. 3). These results strongly suggest that OmpC and OmpF play essential roles in the arginine and lysine-dependent AR systems.

The survival without the addition of amino acids was higher under anaerobic conditions (Figs. 2, 3). Previous study on survival of $E$. coli reported that the survival was longer in anaerobic than aerobic conditions and that several factors may explain the apparent poor survival of $E$. coli in aerobic conditions. Endogenous energy reserves may burn faster under aerobic conditions. The damage of cellular materials due to the accumulation of reactive oxygen species will contribute to the decreasing survival under aerobic conditions. $^{21)}$

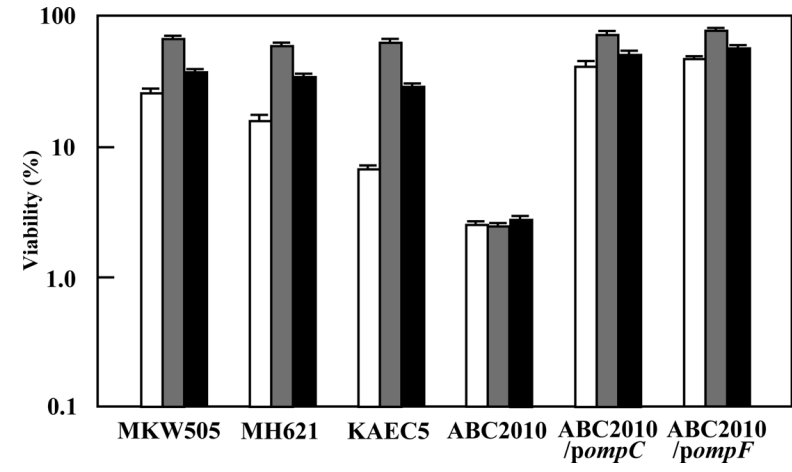

Fig. 3. Effect of Arginine and Lysine on the AR of Various Mutants

MKW505 (omp $\left.C^{+} o m p F^{+}\right)$, MH621 (omp $C^{+}$ompF $\left.F^{-}\right), \operatorname{KAEC5}\left(o m p C^{-}, o m p F^{+}\right)$, $\mathrm{ABC} 2010$ (omp $C^{-}$omp $F^{-}$), $\mathrm{ABC} 2010$ containing pompC, and $\mathrm{ABC} 2010$ containing pompF were grown anaerobically at $\mathrm{pH} 5.5$, and their viability was measured after acidic challenge at $\mathrm{pH} 2.5$ for $1 \mathrm{~h}$, as described in Materials and Methods. One millimolar arginine or lysine was added to the medium at $\mathrm{pH} 5.5$, as indicated below. Symbols: white bars, the viability measured without amino acids; grey bars, the viability measured in the presence of arginine; black bars, the viability measured in the presence of lysine.

(A)

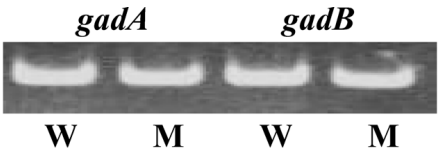

(B)

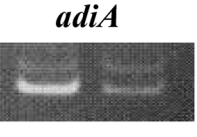

(C)

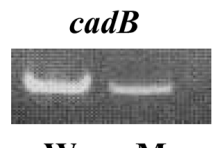

W M

W $\quad \mathbf{M}$

(D)

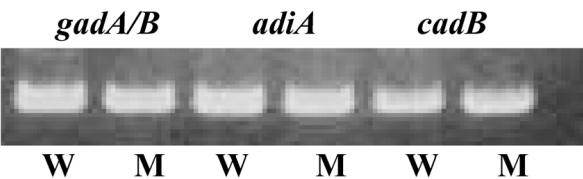

Fig. 4. Expression of $\operatorname{gad} A, \operatorname{gadB}$, adiA, and $c a d B$

The levels of mRNA were measured with RT-PCR. MKW505 (ompC $C^{+}$ompF $\left.F^{+}, \mathrm{W}\right)$ and $\mathrm{ABC} 2010$ (ompC $\mathrm{C}^{-} \mathrm{ompF}^{-}, \mathrm{M}$ ) were cultured aerobically in EG-medium $\mathrm{pH} 5.5$ containing $1 \mathrm{~mm}$ glutamate (A), or anaerobically in EG-medium $\mathrm{pH} 5.5$ containing $1 \mathrm{~mm}$ arginine (B) or lysine (C). (D) The level of 16S rRNA was used as a control.

Expression Levels of Glutamate, Arginine, and Lysine Decarboxylases in the ompC and ompF Deficient Mutant The results described above suggested that the expression of the genes coding for decarboxylases was affected by the deletion of $o m p C$ and $o m p F$. We measured the mRNA levels of the double deficient mutants. After the addition of $1 \mathrm{~mm}$ glutamate, the expression levels of $\operatorname{gad} A$ and $\operatorname{gadB}$ were not significantly affected by the deletion of both ompC and $о m p F$ under aerobic conditions, while the expression of both adiA and $c a d B$ in the presence of $1 \mathrm{~mm}$ arginine or lysine was significantly repressed in the double deficient mutant (Fig. 4).

These results indicate that $\mathrm{OmpC}$ and $\mathrm{OmpF}$ are essential for the full induction of arginine and lysine decarboxylase expression, while the expression of glutamate decarboxylases is not significantly affected by the deletion of ompC and ompF.

The Activities of Arginine, Lysine, and Glutamate Decarboxylations in ompC and ompF Deficient Mutant As described above, the addition of lysine or arginine did not 


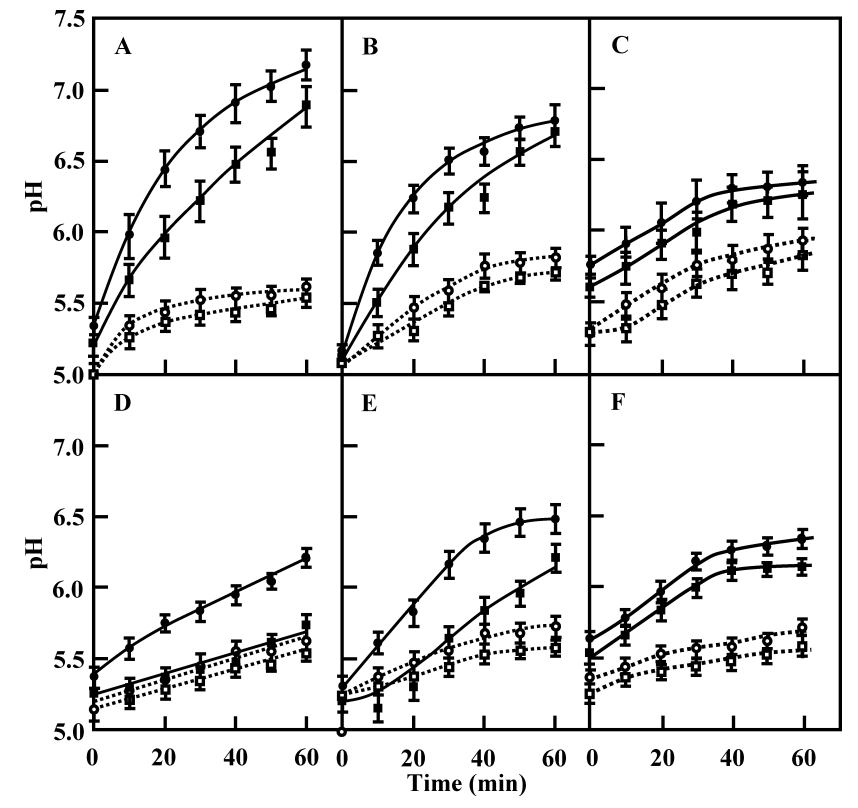

Fig. 5. Activity of Arginine and Lysine Decarboxylases

MKW505 (omp $\left.C^{+} o m p F^{+}\right)$and $\mathrm{ABC} 2010\left(\right.$ omp $C^{-}$ompF $\left.F^{-}\right)$were grown anaerobically in the presence of $1 \mathrm{~mm}$ arginine (A and $\mathrm{D}$ ) or lysine (B and $\mathrm{E}$ ), or aerobically in the presence of $1 \mathrm{~mm}$ glutamate $(\mathrm{C}$ and $\mathrm{F})$ until their absorbance at $600 \mathrm{~nm}$ reached 0.3 . After the cells had been harvested, the $\mathrm{pH}$ change was measured in the presence of arginine (A and D), lysine (B and E), or glutamate (C and F), as described Materials an Methods. Triton X-100 was added in A, B, and C. Symbols: $\bullet$, MKW505 with amino acids; $\mathrm{ABC} 2010$ with amino acids; $\bigcirc$, MKW505 without amino acids; $\square$ ABC2010 without amino acids. The mean values and standard deviations obtained from three independent experiments are represented.

significantly increase survival in the $\operatorname{sppC}$ and $o m p F$ double mutant. Next, the conversion of amino acids to amines was measured. After membrane permeability had been disrupted with Triton X-100, the activity of the double deficient mutant was slightly lower than that of the wild type (Figs. 5A, B). In contrast, the conversion of arginine and lysine was repressed in the double deficient mutant in the absence of Triton X-100 (Figs. 5D, E). The conversion of glutamate was not repressed in the double mutant with and without Triton X-100 (Figs. $5 \mathrm{C}, \mathrm{F})$. These results have revealed that $\mathrm{OmpC}$ and $\mathrm{OmpF}$ support the survival via the transport of arginine and lysine through these porins. Glutamate may be able to move across the outer membrane via other routes.

\section{DISCUSSION}

E. coli is generally considered to be a neutralophilic organism, but both commensal and pathogenic E. coli are capable of surviving in extremely acidic environments $(\mathrm{pH} \mathrm{2.5)}$ for several hours. ${ }^{22,23)} \mathrm{OmpC}$ and $\mathrm{OmpF}$ play important roles in the membrane transport of solutes, such as amino acids, in $E$. coli and other Gram-negative bacteria. ${ }^{24)}$ However, an $E$. coli mutant that was deficient in both ompC and ompF was shown to grow under conventional growth conditions. ${ }^{12)}$ The roles of these porins may differ under different $\mathrm{pH}$ conditions because the expression levels of $o m p C$ and $o m p F$ were obviously altered by changes in $\mathrm{pH}^{25)}$

Concerning the importance of $\mathrm{OmpC}$ and $\mathrm{OmpF}$, we constructed an ompC/ompF double mutant to investigate their roles in AR. It was previously reported that a lack of porin proteins had a significant impact on $E$. coli in natural and fil- tered sea water. $^{26)}$ Our experiments indicated that in the absence of amino acid supplementation, the double mutant was more sensitive to acidic stress than the single mutants. Moreover, AR was highest after complementation of the single mutants with plasmids containing the $\operatorname{ompC}$ or $o m p F$ gene.

Several amino acid decarboxylases have been identified in E. coli, ${ }^{27)}$ and the presence of glutamate, arginine, and lysine decarboxylases has been linked to the AR mechanisms dependent on these amino acids. ${ }^{28)}$ In a previous study, it was shown that the glutamate-dependent AR system is essential for maximal protection of E. coli O157:H7 against both oxidative and acidic stress. ${ }^{29)}$ On the contrary, acidic adapted $S$. Typhimurium survived better at $\mathrm{pH} 2.5$ in the presence of arginine and lysine, but glutamate did not exert any protective effect. ${ }^{30)}$ In this study, we examined how the deletion of ompC and $о m p F$ affects the major acidic resistance systems, which have been characterized in E. coli. ${ }^{31)}$ Our data suggested that $\mathrm{OmpC}$ and $\mathrm{OmpF}$ play integral roles in the induction of both AR3 and AR4 under anaerobic conditions.

A previous observation suggested that porin proteins control the permeability of the outer membrane to small hydrophilic molecules, ${ }^{32)}$ but no previous report has shown that the transport activity of amino acids is influenced by the absence of $o m p C$ and $o m p F$ under near neutral conditions. Our results demonstrated that the conversion of arginine and lysine in intact cells was repressed by the deletion of ompC and $o m p F$ more strongly than that of cells treated with Triton X100 (Fig. 5). In contrast, the decarboxylation of glutamate was not affected by such deletion (Fig. 5). The deletion of ompC and $о m p F$ did not have the marked decrease in $\mathrm{pH}$ at the saturated level in the presence of lysine (Fig. 5E). It was proposed that the conversion of amino acids to amines increases the cytoplasmic $\mathrm{pH}$ and that this increase is important for survival under extremely acidic conditions. ${ }^{420)}$ Based on their proposal, protons move from the outside to the cytoplasm under acidic conditions, and hence the continuous consumption of cytoplasmic protons via amino acid decarboxylation is required for keeping a high cytoplasmic $\mathrm{pH}$. These results suggested that the transport of arginine, lysine, and their decarboxylated amines was important for survival under acidic conditions, while the glutamate transportation through these porins has no essential role in the glutamate dependent AR.

In the absence of amino acids supplementation, AR was decreased by the deletion of both ompC and $o m p F$, leading us to conclude that the membrane transport of solutes other than amino acids is also essential for survival under acidic conditions in the absence of amino acids. We used the chemical defined medium in the present study as described in Materials and Methods. Glucose increased the AR of ABC2010 as well as the wild type MKW505 (data not shown), and citric acid is not metabolized in E. coli. Therefore, the export of some endogenous solutes might be required for survival in acidic medium containing no exogenous amino acids.

\section{REFERENCES}

1) Foster J. W., Curr. Opin. Microbiol., 2, 170-174 (1999).

2) Hersh B. M., Farooq F. T., Barstad D. N., Blankenshorn D. L., Slonczewski J. L., J. Bacteriol., 178, 3978-3981 (1996).

3) Castanie-Cornet M. P., Penfound, T. A., Smith D., Elliott J. F., Foster J. W., J. Bacteriol., 181, 3525-3535 (1999). 
4) Richard H. T., Foster J. W., Adv. Appl. Microbiol., 52, 167-186 (2003).

5) Iyer R., Williams C., Miller C., J. Bacteriol., 185, 6556-6561 (2003).

6) Auger E. A., Redding K. E., Plumb T., Childs L. C., Meng S. Y., Bennett G. N., Mol. Microbiol., 3, 609-620 (1989).

7) Nikaido H., Nakae T., Adv. Microb. Physiol., 20, 163-250 (1979).

8) Nikaido H., Vaara M., Microbiol. Rev., 49, 1-32 (1985).

9) Osborn M. J., Wu H. C. P., Ann. Rev. Microb., 34, 369-422 (1980).

10) Lugtenberg B., Van Alphen L., Biochim. Biophys. Acta, 737, 51-115 (1983).

11) Özkanca R., Şahin N., Kariptaş E., Flint K. P., J. Appl. Microb., 92, 1097-1104 (2002).

12) Kaeriyama M., Machida K., Kitakaze A., Wang H., Lao Q., Fukamachi T., Saito H., Kobayashi H., Lett. Appl. Microbiol., 42, 195-201 (2006).

13) Bang I. S., Kim B. H., Foster J. W., Park Y. K., J. Bacteriol., 182, 2245-2252 (2000).

14) Gibson M. M., Ellis E. M., Graeme-Cook K. A., Higgins C. F., Mol. Gen. Genet., 207, 120-129 (1987).

15) Higashitani A., Nishimura Y., Hara H., Aiba H., Mizuno T., Horiuchi K., Mol. Gen. Genet., 240, 339-347 (1993).

16) Jensen K. F., J. Bacteriol., 175, 3401-3407 (1993).

17) Jung I. L., Kim I. G., J. Biol. Chem., 278, 22846-22852 (2003).

18) Lennox E. S., Virology, 1, 190-206 (1955).

19) Bhagwat A. A., Chan L., Han R., Tan J., Kothary M., Jean-Gilles J., Tall B. D., Infect. Immun., 73, 4993-5003 (2005).
20) Richard H., Foster J. W., J. Bacteriol., 186, 6032 - 6041 (2004).

21) Roslev P., Bjergbaek L. A., Hesselsoe M., J. Appl. Microbiol., 96, 938-945 (2004)

22) Foster J. W., Nat. Rev. Microbiol., 2, 898-907 (2004).

23) Large T. M., Walk S. T., Whittam T. S., Appl. Environ. Microbiol., 71, $2493-2500$ (2005)

24) Sato M., Machida K., Arikado E., Saito H., Kagekawa T., Kobayashi H., Appl. Environ. Microbiol., 66, 943-947 (2000).

25) Heyde M., Portalier R., Mol. Gen. Genet., 208, 511 -517 (1987).

26) Darcan C., Ozkanca R., Flint K. P., Lett. Appl. Microbiol., 37, 380385 (2003).

27) Gale E. F., Adv. Enzymol., 6, 1-32 (1946)

28) Guilfoyle D. E., Hirshfield I. N., Lett. Appl. Microbiol., 22, 393-396 (1996).

29) Bearson B. L., Lee I. S., Casey T. A., Microbiology, 155, 805-812 (2009).

30) Álvarez-Ordóñeza A., Fernándeza A., Bernardoa A., López M., Int. J. Food Microbiol., 136, 278-282 (2009).

31) Casalino M., Prosseda G., Barbagallo M., Iacobino A., Ceccarini P., Latella M. C., Nicoletti M., Colonna B., Int. J. Med. Microbiol., 300, 289-295 (2010)

32) Pratt L. A., Hsing W., Gibson K. E., Silhavy T. J., Mol. Microbiol., 20, 911-917 (1996).

33) Datsenko K. A., Wanner B. L., Proc. Natl. Acad. Sci. U.S.A., 97, $6640-6645(2000)$ 